\title{
A Human-Robot Interface With Supervised Learning
}

This paper was downloaded from TechRxiv (https://www.techrxiv.org).

\section{LICENSE}

CC BY 4.0

SUBMISSION DATE / POSTED DATE

05-07-2021 / 07-07-2021

CITATION

Ubosi, Dozie (2021): A Human-Robot Interface With Supervised Learning. TechRxiv. Preprint. https://doi.org/10.36227/techrxiv.14908041.v1

$\mathrm{DOI}$

10.36227/techrxiv.14908041.v1 


\section{A Human-Robot Interface With Supervised Learning Written by: Dozie Ubosi, 2nd year Mechanical Engineering student at University of Guelph}

Email: cubosiduoguelph.ca

\section{Abstract}

In the world we live in today technology is advancing at a rapid rate, predictions say we will reach the singularity at some point in the future but many experts agree that society is not there yet. With phones that have transistors smaller than we can see and automated cars, the machine learning field has been gathering lots of attention due to its infinite applications. Algorithms can be put in place to make accurate predictions. Society is now seeing many sectors being revolutionized by technology and more efficient methods that do not require human labour. However, to reach that stage there is a lot of hard coding behind the scenes and manually entering testing parameters in order to train machine learning models. Life is being made easier by a certain group of people doing really hard things. In mechatronic hands linear actuators react to changes in voltage read by a sensor to produce motion. Extraction of the signals is important for the analysis of the grip strength. When the grip strength is further analyzed a human robot-interface can be created through personalized threshold settings.

\section{Objectives}

An electromyographic (EMG) sensor used with a serial plotter will be used to visualize the voltage forearm muscles produce for different people. The main purpose of this experiment is to analyze the grip strengths of various individuals to further understand the factors that influence the grip strength of limb-different individuals. Two Machine learning techniques, Linear regression and Pearson Correlation will be used to analyze the data.

\section{Materials}

1. Breadboard

2. Jumper wires

3. $9 \mathrm{~V}$ batteries $\mathrm{x} 2$

4. Battery connectors $\times 3$

5. Arduino UNO

6. Electromyographic Sensor

7. Electrodes $\times 3$

\section{Methods}


Set up the schematic below then attach electrodes to the forearm of each participant. Flex repeatedly and read the signals from the serial monitor/plotter on Arduino IDE.

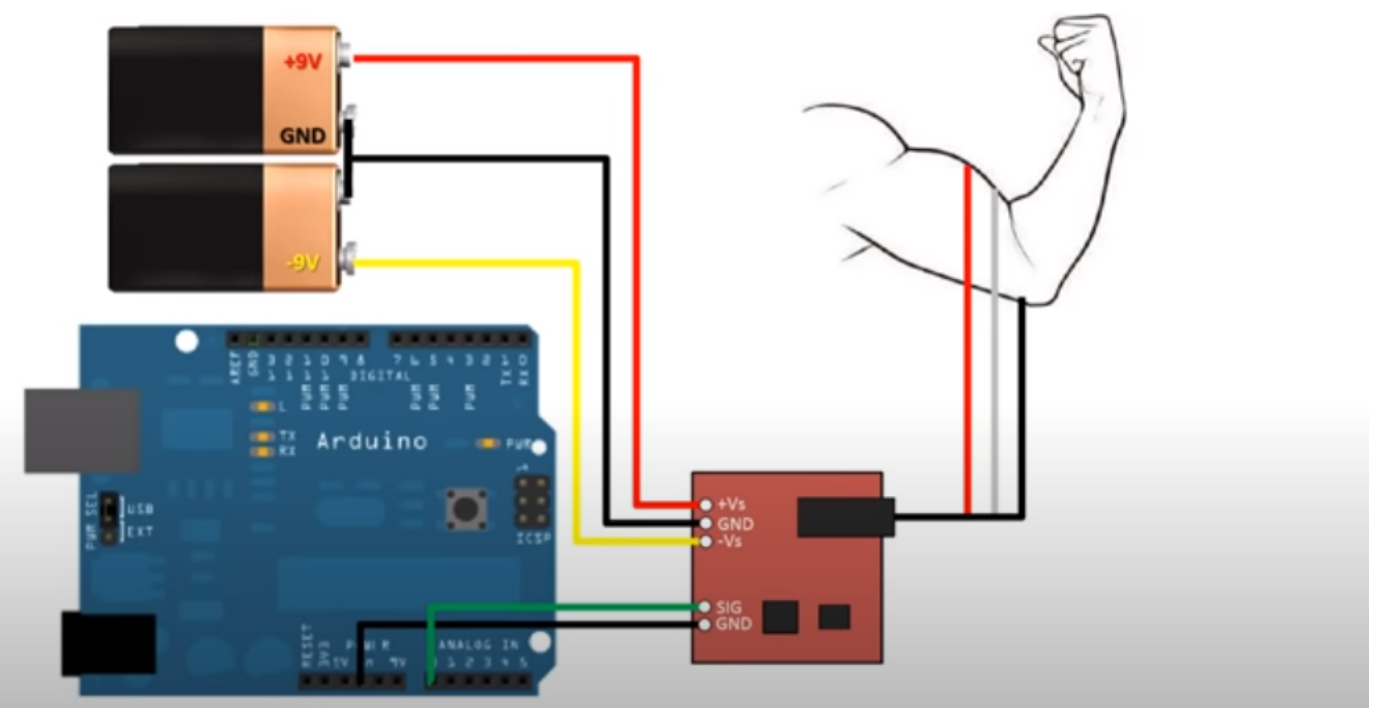

Figure 1.1 EMG schematic diagram

\section{Results}

The average age of participants was 26.6 with a standard deviation of 12.22 .

\begin{tabular}{|l|l|l|l|}
\hline Age & Gender & Weight (lbs) & $\begin{array}{l}\text { Grip } \\
\text { Strength }(\mu \mathrm{V})\end{array}$ \\
\hline 19 & M & 165 & 400 \\
\hline 20 & M & 250 & 620 \\
\hline 48 & F & 176 & 290 \\
\hline 14 & F & 202 & 340 \\
\hline 32 & M & 165 & 450 \\
\hline
\end{tabular}

Table 1.1 Dataset for activity 
Grip Strength vs Age

800

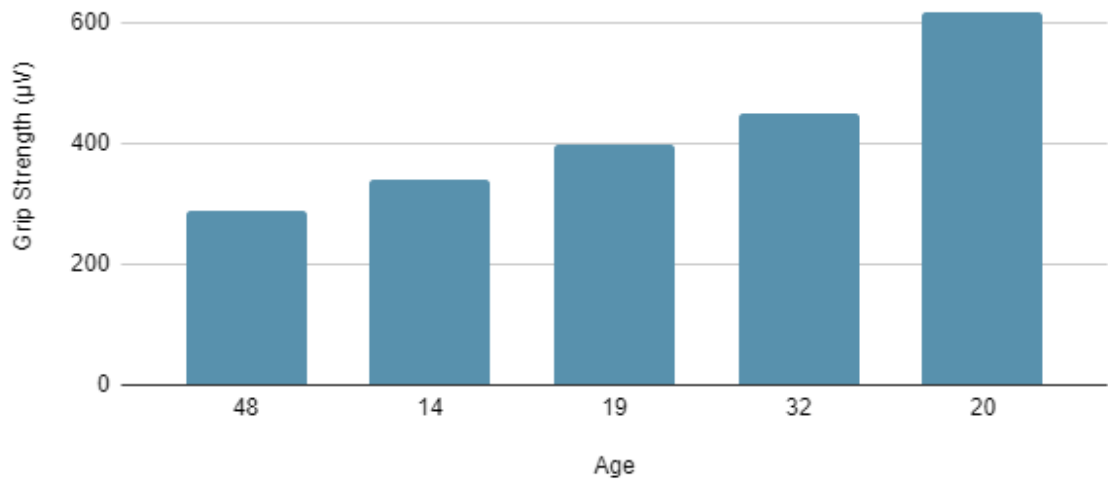

Figure 1.2 Grip strength vs Age

Grip Strength vs Gender

800

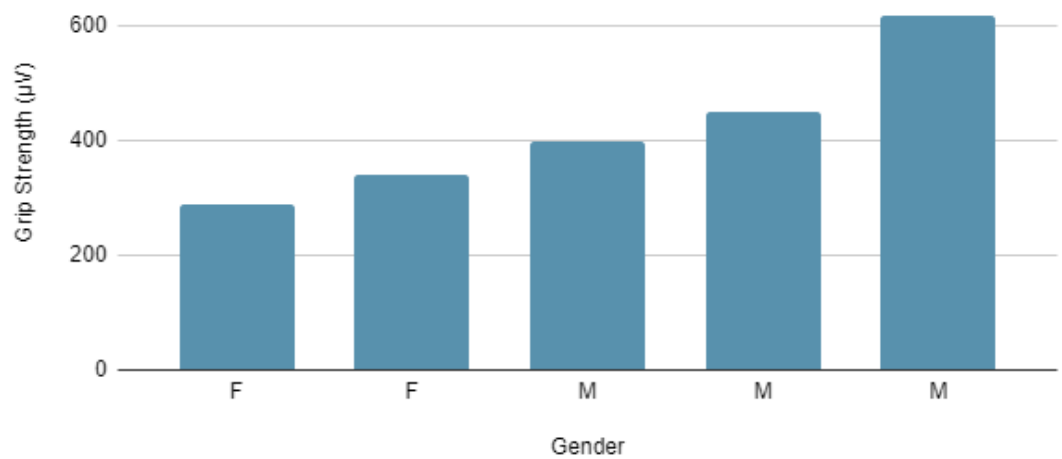

Figure 1.3 Grip strength vs Gender

Grip Strength vs Weight

800

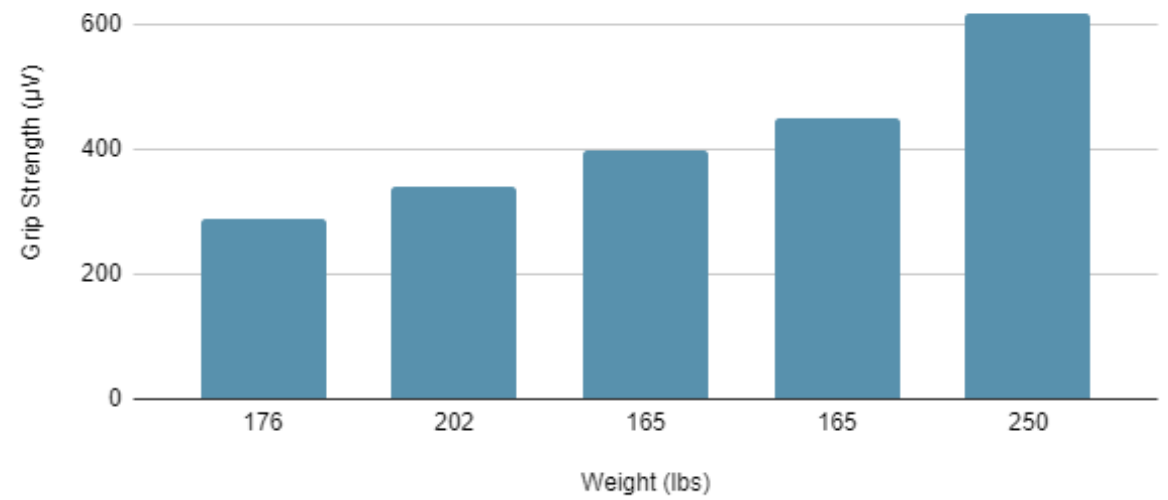

Figure 1.4 Grip strength vs Weight 


\section{Regression equation for Grip strength vs Age}

Sum of $X=133$

Sum of $Y=2100$

Mean $X=26.6$

Mean $Y=420$

Sum of squares $\left(S_{X}\right)=747.2$

Sum of products $(\mathrm{SP})=-2780$

Regression Equation $=\mathrm{y}=\mathrm{mX}+\mathrm{b}$

$\mathrm{b}=\mathrm{SP} / \mathrm{SS}_{\mathrm{x}}=-2780 / 747.2=-3.72056$

$\mathrm{a}=\mathrm{M}_{\mathrm{Y}}-\mathrm{bM}_{\mathrm{X}}=420-(-3.72 * 26.6)=518.96681$

$Y=-3.72056 X+518.96681$

\section{Regression equation for Grip strength vs Weight}

Sum of $X=958$

Sum of $Y=2100$

Mean $X=191.6$

Mean $Y=420$

Sum of squares $\left(\mathrm{SS}_{\mathrm{X}}\right)=5177.2$

Sum of products $(\mathrm{SP})=12610$

Regression Equation $=\mathrm{y}=\mathrm{mX}+\mathrm{b}$

$\mathrm{b}=\mathrm{SP} / \mathrm{SS}_{\mathrm{X}}=12610 / 5177.2=2.43568$

$\mathrm{a}=\mathrm{M}_{\mathrm{Y}}-\mathrm{bM}_{\mathrm{X}}=420-(2.44 * 191.6)=-46.6762$

$Y=2.43568 X-46.6762$

Pearson correlation Formula:

$r=\frac{1}{n-1}\left(\frac{\sum_{x} \sum_{y}(x-\bar{x})(y-\bar{y})}{s_{x} s_{y}}\right)$

Pearson Correlation coefficient for Grip strength vs Age

$\mathrm{X}$ Values

$\Sigma=133$

Mean $=26.6$

$\sum\left(\mathrm{X}-\mathrm{M}_{\mathrm{x}}\right)^{2}=\mathrm{SS}_{\mathrm{x}}=747.2$

Y Values

$\Sigma=2100$ 


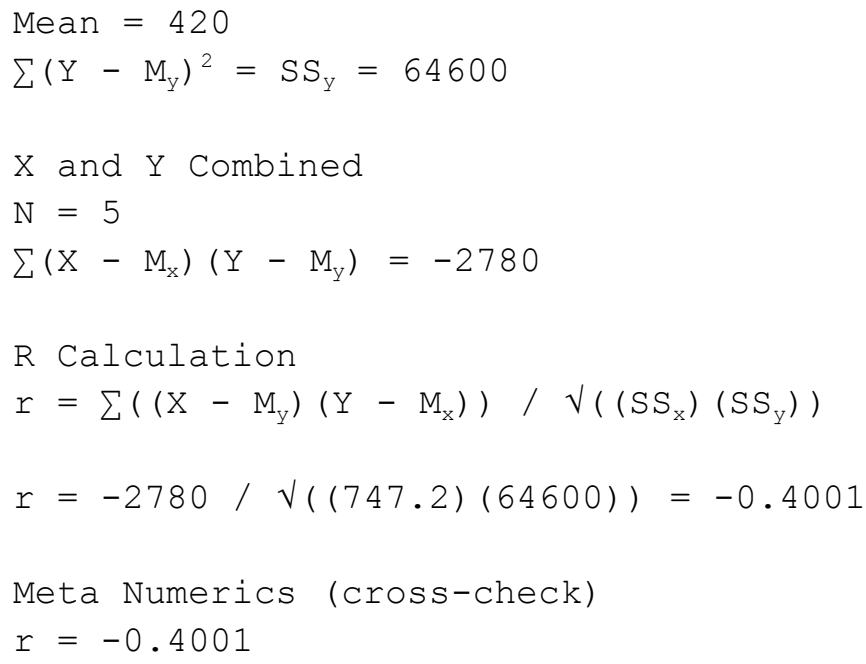

Pearson Correlation coefficient for Grip strength vs Weight

$\mathrm{X}$ Values

$\Sigma=958$

Mean $=191.6$

$\sum\left(X-M_{x}\right)^{2}=S S_{x}=5177.2$

Y Values

$\Sigma=2100$

Mean $=420$

$\sum\left(\mathrm{Y}-\mathrm{M}_{\mathrm{y}}\right)^{2}=\mathrm{SS}_{\mathrm{y}}=64600$

$X$ and $Y$ Combined

$\mathrm{N}=5$

$\sum\left(X-M_{X}\right)\left(Y-M_{Y}\right)=12610$

R Calculation

$r=\sum\left(\left(X-M_{Y}\right)\left(Y-M_{X}\right)\right) / V\left(\left(S S_{X}\right)\left(S S_{Y}\right)\right)$

$r=12610 / V((5177.2)(64600))=0.6895$

Meta Numerics (cross-check)

$r=0.6895$

Moderate positive correlation indicates that variables move together.

\section{Conclusion and Sources of Error}

With 5 participants for data collection the correlation values still made a lot of sense. A negative correlation for grip strength vs age means as age goes up grip strength goes down which is factual because as humans get older muscle energy goes down however the size of the dataset has to be considered and a gigantic data set is required to see 
the trends. For the grip strength vs weight, the correlation yielded was a moderate positive which indicates that both values move together, as weight goes up, grip strength goes up. Other factors such as gender and exercise habits should also be considered but those are not numerical factors so they do not fit into calculations. In conclusion, all the results were useful and the applications of linear regression and pearson correlation for predicting grip strengths for creating devices for limb different individuals is endless. 
Sources

https://www.socscistatistics.com/tests/regression/default.aspx

https://www.socscistatistics.com/tests/pearson/default2.aspx 